\title{
A Coleção Linhares em meio digital ${ }^{*}$
}

\section{Linhares Collection Digital Library}

\author{
VILMA MOREIRA DOS SANTOS \\ Arquivo Público Mineiro \\ Av. João Pinheiro, 372. 30130-180. Bairro Funcionários \\ Belo Horizonte. Brasil \\ vilma.santos@cultura.mg.gov.br
}

\section{SILVANA APARECIDA SILVA DOS SANTOS \\ Escola de Ciência da Informação Universidade Federal de Minas Gerais Av. Antônio Carlos, 6627. 31.270.901 Pampulha. Belo Horizonte. Brasil silvana@ufmg.br}

LUIZ HENRIQUE DOS SANTOS Escola de Ciência da Informação Universidade Federal de Minas Gerais Av. Antônio Carlos, 6627. 31.270.901

Pampulha. Belo Horizonte. Brasil Ihsantos@eci.ufmg.br

RESUMO O Projeto "Criação da Biblioteca Digital Linhares", elaborado por pesquisadores da Universidade Federal de Minas Gerais - UFMG, teve como objetivo conceber e implementar metodologia para preservar e dar acesso à Coleção Linhares, constituída por jornais, revistas e panfletos publicados em Belo Horizonte e colecionados por Joaquim Nabuco Linhares desde 1895, até a sua morte em 1945. Foi adquirida a preço simbólico pela UFMG, em

* Artigo recebido em: 30/03/2011. Aprovado em: 12/07/2011. 
1976, e depositada na Biblioteca Universitária da UFMG. A coleção, considerada de grande importância para a história da imprensa de Belo Horizonte, se encontrava em acelerado processo de deterioração. A biblioteca digital foi construída com base na proposta metodológica do processo híbrido, que preconiza a utilização da microfilmagem para preservar o acervo e a digitalização, via microfilme, para proporcionar o acesso. O projeto foi desenvolvido de forma colaborativa, envolvendo pesquisadores e servidores da Escola de Ciência da Informação, do Departamento de História e da Biblioteca Universitária da UFMG. Disponível em: http://linhares.eci.ufmg.br

Palavras-chave Coleção Linhares, bibliotecas digitais, digitalização de acervos

ABSTRACT Linhares Digital Library Project, carried out by researchers and technical staff of Federal University of Minas Gerais - UFMG, aimed the development and implementation of a digital library methodology to provide access and preservation for newspapers, magazines and pamphlets published in Belo Horizonte, Minas Gerais, Brazil, collected by Joaquim Linhares, since his early youth in 1895, to his death in 1945. The collection was acquired by UFMG from Linhares' inheritors, at a nominal sum and deposited at the University Library. The importance of the collection for the history of Belo Horizonte's press has been highly emphasized by many scholars in the last decades, but the materials had been seriously affected by paper acidity and human damages. The digital library took the hybrid process format: microfilming of the materials to guarantee the preservation aspect and also, the digitalization from the microfilms to provide access. Available at: http://linhares.eci.ufmg.br

Keywords Coleção Linhares, digital libraries, research collections digitalization

\section{O acervo de Joaquim Nabuco Linhares na Universidade Federal de Minas Gerais - UFMG}

Há pelo menos quatro décadas, a UFMG tem se dedicado à tarefa de adquirir acervos notórios em diferentes áreas do conhecimento, por intermédio da Biblioteca Universitária - BU. A coleção de jornais e revistas de Linhares foi um dos primeiros acervos a serem recolhidos e tudo começou quando, em 1974, a família de Linhares manifestou o desejo de depositar o seu acervo na Universidade.

A Comissão Especial nomeada pelo Conselho Universitário para avaliar a coleção foi integrada pelos professores José Mendonça, Wilton Cardoso e Isis Paim, então Diretora da BU, e recomendou a sua aquisição, ressal- 
tando "a qualidade do acervo e as boas condições de sua conservação". 1 O acervo foi adquirido a preço simbólico pela UFMG, em 1976, e integrado ao Setor de Coleções Especiais da Biblioteca, passando a ser designado como "Coleção Linhares". Desde então, vem sendo amplamente consultado por pesquisadores de diversas áreas do conhecimento, tais como: história, sociologia, letras, economia, dentre outras.

Ao ser incorporado ao Setor de Coleções Especiais, o material foi organizado nas estantes por ordem alfabética de títulos. Em tempos mais recentes, a equipe responsável pelo Setor elaborou projetos de conservação específicos para o acervo, obtendo recursos junto a órgãos de fomento. Os projetos tiveram como objetivo melhorar as condições de armazenamento da coleção, para deter ou pelo menos minimizar os problemas de acidificação do papel. Os jornais foram acondicionados em envelopes individuais de papel especial, por título, mantendo-se a ordem alfabética inicial. As revistas foram armazenadas em porta-revistas, também de acordo com a ordem alfabética.

Os procedimentos de conservação foram de grande importância para minimizar os problemas do papel, mas, como já se esperava, não seriam suficientes para dar conta do processo acelerado de acidez, inerente à baixa qualidade do papel utilizado na impressão dos jornais. Esse processo de deterioração submeteu a equipe responsável pelo acervo a um estado de tensão nada fácil de ser resolvido: o acesso ao acervo de Linhares ameaçava de forma cada vez mais acelerada a sua preservação.

Paralelamente aos trabalhos de organização e preservação, uma nova iniciativa viria intervir de forma relevante para a visibilidade e divulgação do acervo. Com a aproximação das comemorações do centenário da cidade de Belo Horizonte, a Fundação João Pinheiro, por intermédio do Centro de Estudos Históricos e Culturais, lançou a Coleção Centenário, "com o intuito de contribuir, de forma permanente e significativa, para essas festividades, refletindo sobre o processo de criação e evolução da Capital, através do relato de suas muitas histórias".2

Pesquisadores da UFMG, também interessados na temática do centenário de Belo Horizonte, convidaram a Fundação João Pinheiro para participar como co-editora da publicação da obra de Linhares. O catálogo Itinerário da Imprensa de Belo Horizonte: 1895-1954 foi publicado em 1995, dois anos antes da data do centenário da cidade e como primeiro volume da Coleção Centenário.

O Itinerário da Imprensa de Belo Horizonte listou os 839 títulos de publicações periódicas - jornais, revistas e panfletos - colecionados e cata-

1 CASTRO, Maria Ceres Pimenta S. Efêmeros e permanentes: os ardis da memória da imprensa de Belo Horizonte. In: LINHARES, Joaquim Nabuco. Itinerário da imprensa de Belo Horizonte: 1895-1954. Belo Horizonte: Fundação João Pinheiro/Centro de Estudos Históricos e Culturais, 1995, p.16.

2 MARTINS, Roberto Borges. Apresentação. In: LINHARES, Joaquim Nabuco. Itinerário da imprensa de Belo Horizonte, p.9. 
logados por Linhares, acompanhados das respectivas resenhas também elaboradas por ele. A pesquisadora Maria Ceres P. Spíndola de Castro, do Departamento de Comunicação da UFMG, coordenou a equipe responsável pela produção do catálogo e elaborou o estudo e nota biográfica. É neste estudo que encontramos respaldo para discorrer de forma sintética sobre a vida e obra de Linhares. ${ }^{3}$

Linhares nasceu em Ouro Preto em 1880 e se transferiu para Belo Horizonte quando da mudança da capital. Desde então, se lançou à tarefa de coletar exemplares de jornais e revistas que surgiram e desapareceram durante o tempo em que residiu na cidade. À medida que reunia as publicações, Linhares se dedicava cuidadosamente à catalogação do material recolhido, descrevendo a sua natureza, formato, propriedade, periodicidade, redação e duração.

Na visão de Maria Ceres S. Castro, Linhares não se limitou ao desejo de colecionar o "objeto de sua paixão" e produziu a sua monografia, reunindo 839 resenhas de títulos que circularam em Belo Horizonte no período de 1895 a 1954.

Dotado de personalidade metódica e senso de organização, Linhares corria em busca das publicações, assim que the chegava aos ouvidos qualquer notícia sobre o aparecimento de um novo título. Todos eram colecionados, sem que ele introduzisse critério de julgamento, seja de efemeridade ou qualquer outra característica. Assim, Linhares reúne jornais da mais variada natureza:

Há jornais de natureza política; aparecem os chamados noticiosos, precursores da imprensa moderna de nossos dias; surgem os literários e culturais, os humorísticos, os associativos, os esportivos, os de operários, de italianos, de árabes, de alemães; folhas católicas, protestantes, maçônicas, espíritas; os boletins e revistas estudantis e universitários; jornais de blocos carnavalescos; panfletos de reclames publicitários, enfim, uma multiplicidade de formas e de temáticas, a construir imagens distintas da cidade e de seu cotidiano. ${ }^{4}$

O Itinerário da Imprensa de Belo Horizonte foi publicado em 1995, quando se completavam quase duas décadas da chegada do acervo à Biblioteca Universitária e de sua imediata disponibilização para consulta. Ao escrever o texto de apresentação do Itinerário da Imprensa de Belo Horizonte, Roberto B. Martins, então presidente da Fundação João Pinheiro, assinalou a preciosidade da coleção de Linhares e já anunciava o seu estado precário, ao mesmo tempo sensibilizando novos parceiros para a obtenção de recursos financeiros a serem empregados em sua conservação,

3 CASTRO, Maria Ceres Pimenta S. Efêmeros e permanentes.

4 CASTRO, Maria Ceres Pimenta S. Efêmeros e permanentes. 
manutenção e melhores condições de disponibilização para o público, sem comprometimento de sua integridade.

\section{O Projeto "Criação da Biblioteca Linhares"}

Ao assinalar o estado da coleção, Roberto B. Martins se referia, provavelmente, a uma questão crucial para os que cuidavam da custódia do acervo. A acidez atingiu níveis elevadíssimos, provocando a quebra do papel, só com o manuseio. As agressões por parte do elemento humano passaram a acontecer, também, com certa frequência: artigos e ilustrações foram recortados como atos de vandalismo, bem como, na tentativa equivocada de se conter o ritmo acelerado da deterioração, foram utilizadas fitas adesivas e outros elementos nocivos ao papel e à tinta.

Os problemas de preservação atingiram tal ponto que os responsáveis pelo acervo perceberam que o acesso à coleção estava prestes a se inviabilizar. É nesse contexto que se insere o projeto em pauta. Era preciso tomar providências emergenciais e pontuais para salvar o acervo e possibilitar o acesso a ele de forma adequada.

O projeto de digitalização da Coleção Linhares foi concebido no início de 2002, por iniciativa da bibliotecária Silvana Aparecida Silva dos Santos, que havia ocupado por vários anos a Chefia do Setor de Coleções Especiais. Apesar de estar ocupando outro cargo na BU, não perdia de vista os problemas do acervo.

Intitulado "Criação da Biblioteca Digital Linhares", o projeto foi elaborado de forma colaborativa por sua idealizadora e por professores do Departamento de Organização e Tratamento da Informação da Escola de Ciência da Informação - ECl, do Departamento de História da Faculdade de Filosofia e Ciências Humanas - FAFICH da UFMG e um servidor especialista em informática, também lotado na ECI.

O Projeto foi submetido ao Edital EDT 1866/2002 da Fundação de Amparo à Pesquisa do Estado de Minas Gerais - FAPEMIG, no âmbito do Programa Uso da Tecnologia Digital no Resgate da Identidade HistóricoCultural de Minas Gerais, vinculado à Secretaria de Estado da Ciência e Tecnologia e de Ensino Superior de Minas Gerais - SECTS/MG. Os recursos solicitados foram atendidos parcialmente, nas rubricas de aquisição de equipamentos, contratação de bolsista de iniciação científica e prestação de serviços.

Cabe ressaltar que a liberação parcial dos recursos e o volume expressivo de títulos e fascículos existentes no acervo levaram a equipe a refletir sobre a prioridade dos materiais a serem tratados. Não foi difícil chegar à conclusão de que deveríamos começar pelos jornais, tendo em vista o estado avançado de acidez do papel. No entanto, os recursos liberados foram suficientes para possibilitar o desenvolvimento da metodologia, a definição 
e aquisição dos equipamentos, bem como para proceder à microfilmagem e digitalização de parte significativa do acervo.

\section{Aspectos conceituais e metodológicos}

Iniciado em dezembro de 2002, o projeto teve como objetivos a criação da Biblioteca Digital Linhares, proporcionando maior visibilidade e acessibilidade à coleção, bem como a realização de estudos e pesquisas concernentes à preservação de acervos notórios e bibliotecas digitais.

Do ponto de vista metodológico, ficou definido que o processo de construção da biblioteca digital deveria se pautar no processo híbrido, ainda pouco utilizado em Minas Gerais, o que dotou o Projeto de um caráter quase inédito.

O processo híbrido foi proposto por estudiosos do campo da preservação de acervos ${ }^{5}$ como forma de atender dois desafios continuamente perseguidos nas instituições detentoras de acervos históricos e notórios: preservar e dar acesso. Os autores dos estudos publicados no âmbito do Projeto Conservação Preventiva em Bibliotecas e Arquivos - CPBA defendiam, à época, o processo híbrido, sob a alegação de que a tecnologia de reprodução digital e a digitalização não se encontravam bem estabelecidas e, ainda, apresentavam alto custo. No entanto, reconheciam que tais tecnologias encerravam uma promessa fundamental para os organismos, na missão de gerar, preservar e otimizar o acesso aos registros do conhecimento.

Por outro lado, consideravam o processo de microfilmagem como o mais eficiente para a preservação de documentos em deterioração, tais como os existentes no acervo de Linhares. Assim, ao produzir o microfilme, tínhamos como objetivo atender o aspecto de preservação e, com a digitalização, seria propiciado o acesso.

Além do aspecto da preservação, havia um fator de natureza técnica que reforçava a opção da microfilmagem. Os jornais e panfletos tinham uma grande variedade de formato, o que exigia a aquisição de um scanner de mesa, capaz de processar jornais também de grandes dimensões. $\mathrm{Na}$ época, este equipamento era de custo muito alto e a ideia de sua aquisição foi também descartada sob a ótica do custo-benefício.

Verificamos, então, que seria necessário o planejamento de uma ação emergencial de preparação do acervo para microfilmagem. O assunto foi discutido com a responsável pelo Laboratório de Preservação do Acervo -

5 A fundamentação teórica sobre a digitalização de acervos no Brasil surgiu de maneira sistematizada no âmbito do Projeto Conservação Preventiva em Bibliotecas e Arquivos, sediado no Arquivo Nacional e coordenado por Ingrid Beck. Este projeto teve como objetivos difundir as atividades de preservação e estimular o intercâmbio e a cooperação entre profissionais atuantes na área de preservação de acervos, desenvolver e manter uma rede de informação com dados atualizados sobre a preservação de acervo e sobre as atividades de preservação nas instituições brasileiras, por meio de publicações, recursos didáticos, seminários e cursos, banco de dados e mapa de preservação. Outras informações no endereço: http://www.arqsp.org.br/cpba/ 
LPA da Escola de Informação da UFMG, bibliotecária Rosemary Tofani, com o objetivo de obter sugestões a respeito dos possíveis encaminhamentos para a questão. Foi sugerida a realização de pequenos reparos, tais como remoção de fitas adesivas, a limpeza de manchas com pó de borracha e a técnica do faceamento, que consiste em pequenas intervenções localizadas nas partes deterioradas. Tais procedimentos, além de possibilitar a microfilmagem dos jornais danificados, tinham como objetivo melhorar a qualidade das imagens. ${ }^{6}$

Recapitulando, o escopo do nosso trabalho ficou assim delineado: o projeto era coordenado e executado por equipe alocada na ECI e na FAFICH, o acervo era custodiado pela Biblioteca Universitária, e a necessidade de licitação para os processos de microfilmagem e digitalização introduziu um terceiro elemento a ser gerenciado - a empresa de microfilmagem, de natureza privada. Esta estrutura era a única viável para a realização do projeto, mas, constituiu, sem sombra de dúvida, em um fator desafiador para a consecução dos nossos objetivos.

As especificações técnicas de microfilmagem e de digitalização foram definidas obedecendo a Lei Brasileira de Microfilmagem ${ }^{7}$ e as especificações de digitalização recomendadas pelo Arquivo Público Mineiro - APM. Adotou-se a mídia DVD com três padrões de imagem: imagem TIFF para preservação, JPEG com compressão 20\% para disponibilização na internet e $70 \%$ para acesso local.

O acervo foi encaminhado para a empresa em lotes formados por um número limitado de títulos de jornais, acondicionados em envelopes e arrolados numa lista em ordem sequencial e alfabética por título, em cada título, o(s) fascículo(s) e nestes, por data, volume/número, número da página e código - representando justamente os itens anteriores (número sequencial, ano, mês, dia, número da página) e as suas dimensões. Esta lista tinha como finalidade resguardar a saída e a devolução do material, controladas fisicamente pela bibliotecária responsável pelo Setor de Coleções Especiais e pelo chefe de Serviços Gerais da Biblioteca Universitária da UFMG. ${ }^{8}$ A lista, preparada preliminarmente pelo bolsista com supervisão da equipe do projeto, serviu como um inventário do acervo - quer no controle do que havia na coleção e eventuais perdas nos registros originais da coleção - ou no controle de saída e devolução do material, pois um dos aspectos relata-

6 A Biblioteca Universitária participou do processo fornecendo material de consumo, especialmente o papel japonês, utilizado na técnica de faceamento. A bolsista do projeto ficou responsável pela tarefa e os trabalhos foram realizados no Laboratório de Preservação do Acervo da Escola de Ciência da Informação.

7 Lei №5.433, de 08 de maio de 1968. Regula a microfilmagem de documentos oficiais e dá outras providências. Decreto Lei n 1.799, de 30 de janeiro de 1996. Regulamenta a Lei nْ5.433, de 8 de maio de 1968.

8 Registramos aqui os nossos agradecimentos à bibliotecária Marlene Lopes, responsável pelo Setor de Coleções Especiais à época da realização do projeto e ao Sr. Valdomiro Arcanjo dos Santos, chefe do Setor de Serviços Gerais. Agradecemos também o apoio irrestrito da então diretora da Biblioteca Universitária, Simone Aparecida dos Santos. 
dos pela bibliotecária responsável pelo acervo foi o da impossibilidade, por falta de recursos humanos, de ser efetuada uma conferência do material no interior dos envelopes, tanto na saída como na chegada.

No entanto, um fator que causou tensão na equipe foi o deslocamento dos jornais, já bastante fragilizados, retirados de um ambiente climatizado e protegido, para uma viagem de ida à empresa de microfilmagem e de volta à BU, embora sempre acompanhados pelo bolsista do Projeto, em uma Kombi comum disponibilizada pela própria Biblioteca. Era longo o percurso por uma via de grande concentração de tráfego em Belo Horizonte. Além disso, ressalta-se que, apesar dos cuidados mantidos pela empresa, o manuseio do material durante o processo de microfilmagem sempre representou um risco à integridade dos documentos.

Na época, a adoção do processo híbrido pelas instituições mineiras era bem recente, quase que circunscrita às iniciativas do APM. Em vista disso, foram realizados dois processos de licitação, porque a equipe julgou prudente não contratar todo o serviço de microfilmagem e digitalização de uma só vez. Planejamos uma primeira licitação para 12.000 imagens, para que houvesse condições de análise do atendimento aos padrões técnicos.

A fase de teste dos padrões se alongou além do previsto em nosso cronograma, devido a uma razão de natureza puramente técnica: o critério de análise das propostas financeiras adotado pela Fundação de Desenvolvimento da Pesquisa - FUNDEP, gerenciadora dos recursos, era o de menor preço, apesar de nossas tentativas, em vão, de introduzir o critério de experiência com acervos em processo de deterioração. Em vista disso, apesar de bem estabelecida no mercado da microfilmagem comercial, a empresa ganhadora não apresentava a experiência desejada.

Não podemos deixar de registrar e agradecer o apoio dos técnicos do APM, que não mediram esforços em se reunir, por várias vezes, com os técnicos da empresa que atendia o projeto, com o objetivo de elucidar as dúvidas, indicando os caminhos a serem seguidos. Nem de enfatizar o envolvimento e interesse da empresa contratada para se inteirar da nova metodologia de trabalho no âmbito de sua atuação. Apesar de todos os problemas enfrentados, permanece um argumento de alcance muito maior: acreditamos ter introduzido no mercado mineiro a demanda por um serviço específico e especializado, podendo mesmo ter contribuído de alguma forma na formação de competência de uma nova empresa para competir no rol desses serviços.

O atraso na fase de testes nos levou a solicitar à FAPEMIG uma prorrogação de quatro meses no Projeto, no que fomos atendidos. Nesta fase, efetuou-se a segunda licitação, dando chance à contratação de uma empresa que comprovou maior experiência na execução dos serviços especificados. Esta fase ocorreu de forma mais tranquila, no entanto, sem nos livrar por completo de alguns problemas, especialmente no tocante ao cumprimento de prazos. 
Foram processadas cerca de 26.000 fotogramas/imagens, portanto, $26 \%$ de uma estimativa de 100.000 itens constantes em nosso projeto inicial. ${ }^{9}$ Os jornais foram processados seguindo a mesma ordem adotada no arranjo do acervo físico - a alfabética, sendo incluídos os jornais até a letra $\mathrm{H}$. Aí ficou estabelecido o corte do que convencionamos chamar de Coleção Linhares Digital - CLD - Fase I. Esta era mais uma contribuição a ser somada às outras levadas a cabo no passado, por pesquisadores e estudiosos preocupados com a manutenção e acessibilidade à coleção de Linhares.

Com grata satisfação, ao redigir este artigo, tivemos conhecimento da realização da fase II da Coleção Linhares Digital, seguindo a mesma linha metodológica da Fase I, já nas etapas finais dos trabalhos. Não podemos deixar de ressaltar que a Fase II está contemplando não só o restante dos jornais e panfletos não incluídos na fase anterior, mas também as revistas. O projeto tem a coordenação do professor Wander Melo Viana e está sendo executado pela BU. ${ }^{10}$

\section{A Montagem da Biblioteca Digital}

A construção da Biblioteca Digital Linhares foi estruturada a partir do planejamento de um website que contemplou basicamente dois tópicos: a descrição do projeto, equipe e apoio institucional e a base de dados contendo as imagens digitalizadas e os descritores de cada jornal tratado. O objetivo dessa base de dados foi trazer uma nova dimensão para a preservação dos materiais fragilizados e prover o acesso simultâneo de vários usuários.

O software foi desenvolvido a partir da linguagem PHP e o gerenciador de base de dados MySQL. O sistema operacional utilizado no equipamento servidor foi o Linux e como gerenciador de web o Apache. Todos são considerados software livres (open source).

Para ter acesso aos jornais, o usuário é conduzido, inicialmente, a uma lista de títulos dos jornais disponíveis (Figura 1). Uma vez selecionado o título, é apresentada uma lista contendo ano(s) e fascículo(s) existente(s) (Figura 2). A partir do ano selecionado, a lista de exemplares daquele ano é mostrada na ordem de mês/dia (Figura 3). Selecionado o exemplar, as imagens de cada página aparecem da seguinte forma: à esquerda da tela os dados de dimensão da imagem (JPEG 20), ao centro a página inicial e, à direita, as imagens em formato reduzido (thumbnails) para as

9 Não foi realizada uma contagem efetiva das páginas a serem microfilmadas/digitalizadas. Foi estabelecida uma estimativa relacionada ao tipo de material do acervo: uma média de 4 a 8 páginas para os jornais e de 30 a 40 páginas para as revistas.

10 As informações sobre a Fase II da CLD foram fornecidas pela bibliotecária Rosemary Tofani Motta, responsável pela execução do projeto, a quem registramos nossos agradecimentos. 
demais (Figura 4). A imagem do centro, ao ser selecionada, permite a visualização em tamanho real.

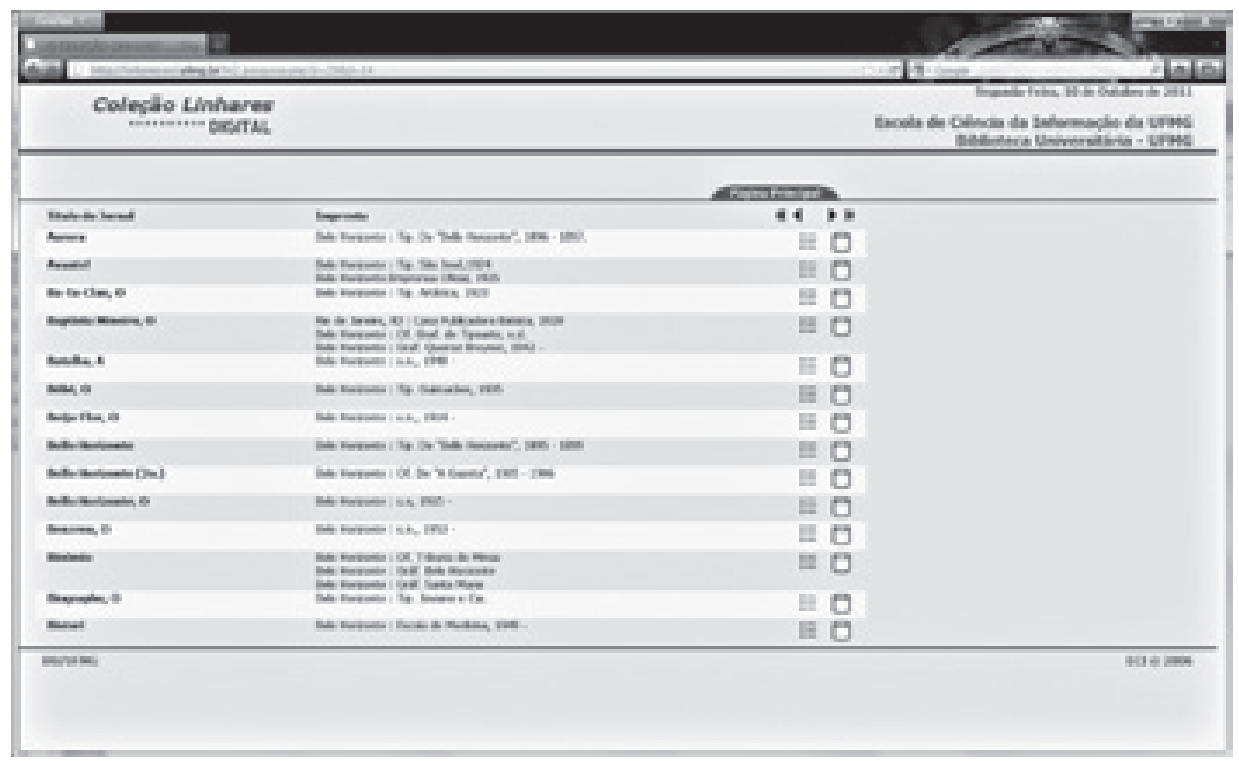

Figura 1: Lista de títulos

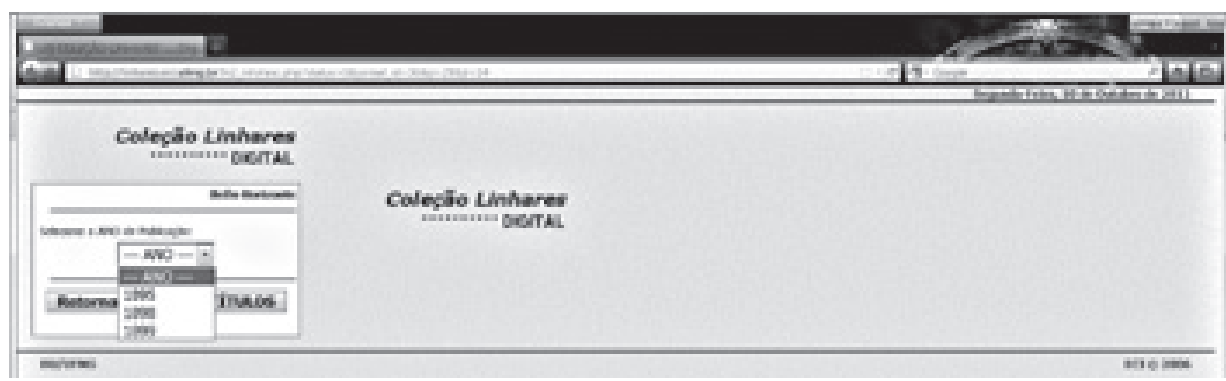

Figura 2: Lista de anos para o título selecionado

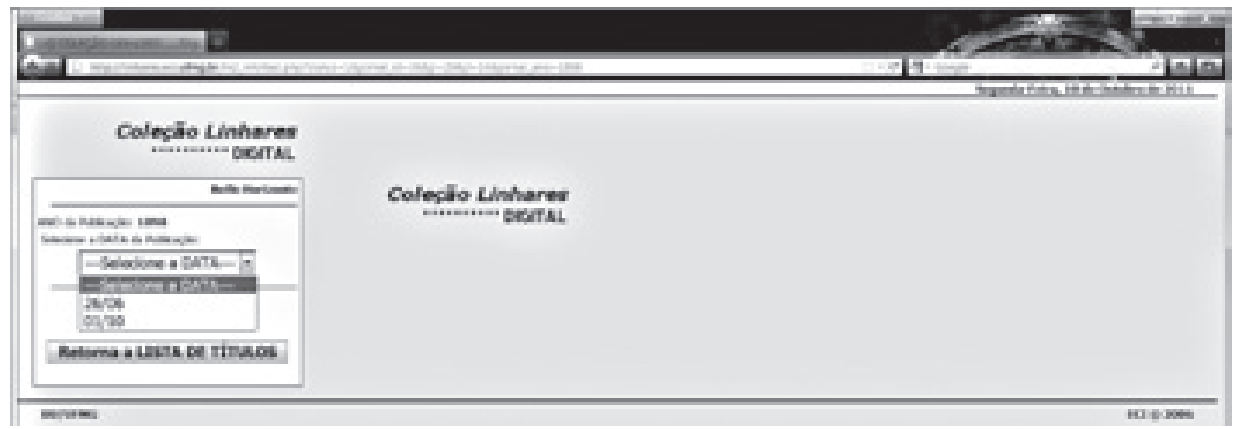

Figura 3: Exemplares por data 


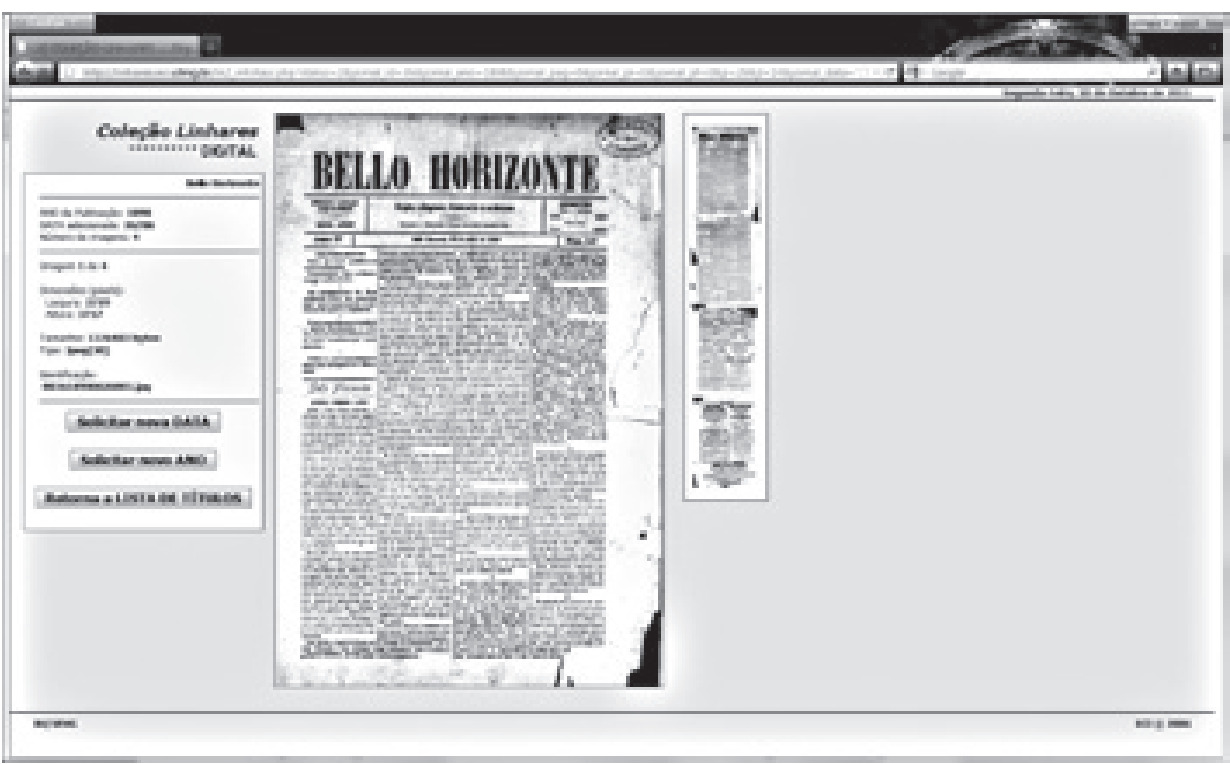

Figura 4: Página digitalizada do jornal

Na lista de títulos também há a opção de apresentação dos descritores identificados no catálogo original do colecionador: título completo; imprenta; descrição física; frequência de distribuição; início/término da publicação; nota(s); tema(s), entendido(s) como os assuntos gerais abordados pela publicação (Figura 5).

As imagens foram organizadas e nomeadas de acordo com a lista encaminhada para a digitalização, ou seja:

*xxxaaaammddninn. JPEG

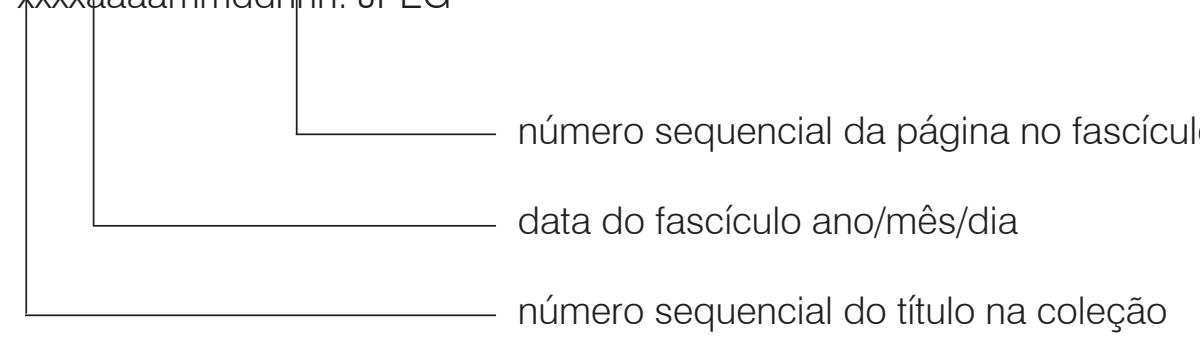

As imagens, em formato JPEG, além de estarem no equipamento servidor, estão reproduzidas em DVD's para efeito de salvaguarda-back-up. As imagens em formato TIFF também estão em DVD's para cópias e consulta quando solicitadas. Todo esse material está no Setor de Coleções Especiais da BU. O equipamento servidor encontra-se sob a guarda e manutenção da ECI/UFMG. 


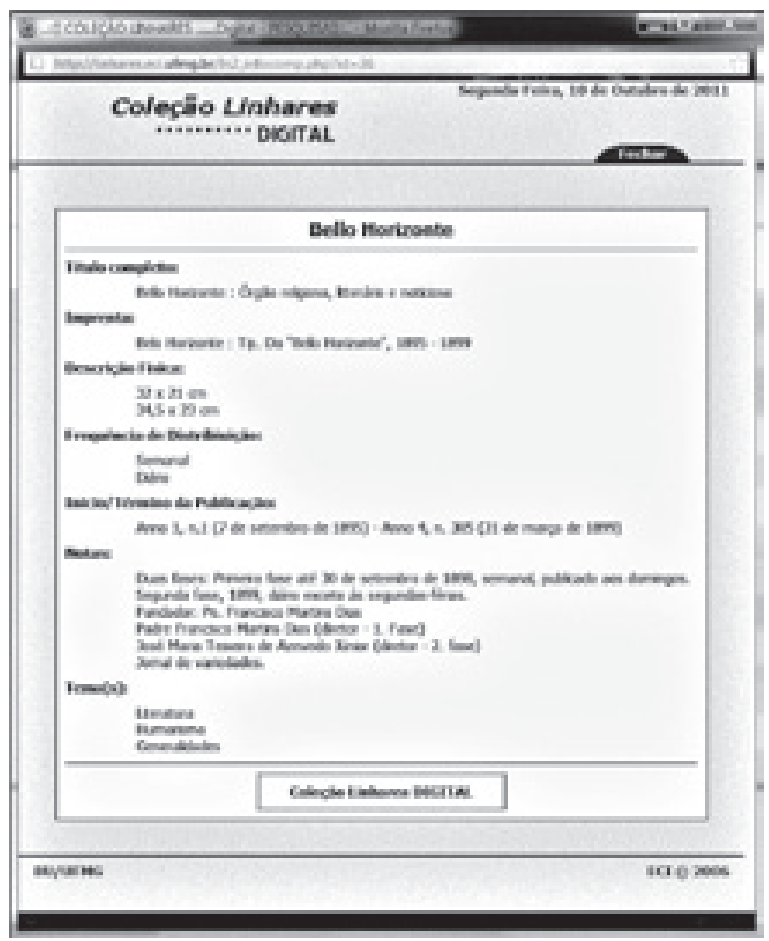

Figura 5: Descritores

A construção do software para apresentação das imagens não considerou a pesquisa nos campos descritores para uma recuperação avançada dos jornais. Também não está contabilizando os acessos à coleção. Não foi discutido, no âmbito do projeto, software de reconhecimento de conteúdo dos textos nas imagens digitalizadas visto que, à época, não existiam softwares livres para isso e o projeto não contemplou recursos para essa rubrica.

\section{A Coleção Linhares após a Digitalização}

Se o estado da coleção antes do processo de reformatação era precário, a expectativa da equipe do projeto não era nada animadora, com relação à situação dos jornais de Linhares, após passarem pela microfilmagem, tendo em vista os problemas já mencionados. Sem sombra de dúvida, a quebra do papel seria ainda mais acentuada com o manuseio para retirada dos envelopes, colocação na planetária e recolocação no envelope. Não tínhamos a menor ideia da viabilidade de guarda dos originais, após a microfilmagem. É bastante surpreendente o relato de Marlene Lopes, dando conta de que "o estado de conservação dos jornais, após a microfilmagem, não foi totalmente desastroso. Aqueles que já apresentavam péssimo estado de conservação ficaram totalmente sem condições de manuseio, 
sendo possível a consulta apenas em meio digital. Mas os de bom estado não sofreram maiores danos."

Marlene Lopes também nos diz que os usuários têm demonstrado satisfação com as facilidades de acesso ao material digitalizado. Mas, a demanda pelos originais ainda continua, proveniente dos pesquisadores mais frequentes da coleção, "alegando algum motivo de problema de acesso ao banco de dados". A consulta aos originais é sempre evitada, já que a digitalização foi conduzida justamente para proporcionar a sua preservação. ${ }^{11}$

Os usuários fazem uso frequente, também, dos rolos de microfilmes, alegando "indisponibilidade do site ou impossibilidade de impressão das imagens digitais, por problemas técnicos". Esta forma de consulta é atendida no Setor, onde há leitora-copiadora de microfilme.

Como desdobramento do projeto e visando dar melhores condições de pesquisa ao usuário, Marlene Lopes sugere a indexação por assunto na base de dados. Esta sugestão está diretamente relacionada à política de tratamento de acervos especiais da Biblioteca Universitária. Outro aspecto a ser ressaltado é que, mesmo atendendo às necessidades de pesquisa, o nível de tratamento sugerido é especializado e, certamente, moroso, considerando o volume da Coleção. Isso sem contar o fato de que o tratamento pormenorizado de uma determinada coleção pode se dar, muitas vezes, com comprometimento de recursos financeiros e humanos a serem empregados no conjunto de acervos da instituição.

A atual responsável pelo Setor de Coleções Especiais ${ }^{12}$ corrobora as informações fornecidas por Marlene Lopes, acrescentando que muitos usuários se mostram surpreendidos, na sala de consulta, com a possibilidade de acesso on-line. A Coleção Linhares é a segunda mais consultada no setor e dispõe hoje de equipamento com monitor LCD de uso exclusivo. $\mathrm{O}$ acesso aos originais ${ }^{13}$ só é permitido quando há problemas de natureza técnica no acesso à base de dados e quando a resolução não atende à leitura. Este problema foi relatado pela empresa prestadora dos serviços de microfilmagem/digitalização, dando conta de que aproximadamente 20\% das imagens não atendiam aos padrões de qualidade necessários ao procedimento. Por outro lado, observou-se que, apesar da deterioração e opacidade de vários exemplares, a legibilidade superou as expectativas. A recuperação nos originais também está comprometida.

11 Em 2007, o projeto "Instalação definitiva e adequação do espaço físico do acervo de obras raras e especiais da UFMG com vistas à conservação e acesso", coordenado por Mário Anacleto Souza Júnior, conservador/restaurador do Centro de Conservação e Restauração da Escola de Belas Artes e financiado pelo Banco Nacional de Desenvolvimento Econômico e Social - BNDES, proporcionou acondicionamento para o acervo de Linhares em arquivo deslizante e em sala climatizada.

12 Registramos nossos agradecimentos à bibliotecária Diná Araújo pelas informações prestadas sobre a utilização da Coleção Linhares, por meio de contato por telefone.

13 Recentemente, foram confeccionadas pastas sob medida em papel filifold para atender à variedade de dimensões dos jornais. 
Uma questão também relatada é a eventual inconsistência entre títulos dos jornais e as imagens a eles associadas. Para isso será necessária a conferência completa do acervo garantindo a coerência das informações da coleção digital. As inconsistências estão sendo resolvidas pelo administrador da CLD, seja por meio do contato direto do usuário, ou por intermédio da chefia do Setor de Coleções Especiais.

\section{Resultados e desafios}

A Coleção Linhares Digital resulta de um conjunto de esforços empreendidos por estudiosos e pesquisadores no decorrer de várias décadas.

Em 1995, decorridos quase 20 anos da aquisição do acervo de Linhares pela UFMG e atendendo aos apelos dirigidos ao poder público por estudiosos mineiros em diferentes oportunidades, foi publicada a monografia de Linhares - o Itinerário da imprensa de Belo Horizonte 1895-1945, sob a forma de catálogo, em edição conjunta da UFMG e Fundação João Pinheiro.

O aspecto da preservação da coleção, reivindicado pelo proofessor José Mendonça ${ }^{14}$ em 1980, só veio a ocorrer em 2005, de forma parcial, com o lançamento da Fase I da Biblioteca Digital Linhares, resultante de projeto financiado pela FAPEMIG e realizado por funcionários técnicoadministrativos e por pesquisadores da Escola de Ciência da Informação e do Departamento de História da UFMG.

A Fase II da Coleção Linhares Digital encontra-se em fase final de execução e resulta, também, de projeto financiado pela FAPEMIG, sob a coordenação de um professor pesquisador da Faculdade de Letras e está sendo executado pela Biblioteca Universitária da UFMG.

O nosso relato demonstra que a preservação do acervo de Linhares, consubstanciada nas fases I e II da biblioteca digital, só foi concretizada após 35 anos de sua aquisição pela UFMG, apesar da microfilmagem se encontrar técnica e legalmente reconhecida desde 1968.

Em vista disso, chamamos a atenção para a dimensão política da aquisição de acervos notórios nos planos nacional e internacional. Tradicionalmente, a universidade desempenha papel preponderante no recolhimento de acervos históricos e notórios, ao lado das bibliotecas públicas locais e nacionais, mas com objetivos pontuais: preservar e propiciar oportunidades de pesquisa. Em muitos casos, as aquisições ocorrem no âmbito de projetos de pesquisas. ${ }^{15}$

Porém, no plano brasileiro e mesmo no plano internacional, a universidade ainda hoje não dispõe de recursos humanos e financeiros para fazer

14 MENDONÇA, José. A imprensa de Belo Horizonte na fase revolucionária (1925-1937) In: Seminário de estudos mineiros. Belo Horizonte. Centro de Estudos Mineiros 1950, n.4, p.45-81.

15 SANTOS, Vilma Moreira dos. Brazilian universities and the management of archives: in search of a new approach. Liverpool: University of Liverpool, 1998. (Tese de doutorado). 
face às atividades de processamento e administração que devem seguir à aquisição. Muitos acervos permanecem por vários anos à espera de recursos a serem captados por pesquisadores nos órgãos de fomento à pesquisa, muitas vezes em condições nada razoáveis de preservação. ${ }^{16} \mathrm{~A}$ trajetória do acervo de Linhares na UFMG pode exemplificar muitas dessas questões. Portanto, a decisão de aquisição de acervos notórios deve sempre ser acompanhada de uma análise do ônus que ela acarreta, quer em relação à administração do acervo, quer em relação às expectativas de consulta por parte dos pesquisadores. ${ }^{17}$

Uma análise dos problemas enfrentados pelos usuários da CLD nos conduz à década de 90, apontada como um marco da digitalização de acervos nas instituições brasileiras. ${ }^{18}$ A experiência do APM data desta época e é assim analisada no contexto das instituições de guarda de acervo por Emerson N. Santana:

Ao longo dos anos, [as instituições] foram construindo sistemas baseados em linguagens e padrões técnicos distintos para cada projeto de digitalização e informatização de fundos e de coleções. Esses sistemas, embora precários, cumpriram o importante papel de facilitar o acesso à documentação durante o acesso à documentação durante o período em que foram utilizados. Essas experimentações serviram, ainda, de laboratório, ampliando os conhecimentos da equipe técnica do APM sobre o uso das novas tecnologias em arquivos. Foram fundamentais para o aprendizado dos funcionários, pois introduziram o debate e a prática da informatização nos diversos setores da instituição. ${ }^{19}$

A Coleção Linhares Digital, cuja montagem se deu no início de 2005, enquadra-se, pelo menos em linhas gerais, na análise de Emerson Nogueira, embora em outro cenário - 0 das bibliotecas. ${ }^{20}$ Era a primeira experiência de construção de uma biblioteca digital empreendida pela equipe do projeto. Em 2002, ao elaborar o projeto, ressaltamos o seu caráter quase inédito, mas, sabemos hoje que todos nós, naquela época, tínhamos a

16 SANTOS, Vilma Moreira dos. Brazilian universities and the management of archives.

17 O Laboratório de Conservação e Pesquisa Documental - Labdoc, ligado à Universidade Federal de São João delRei, tem atuado de uma forma pioneira - uma possível alternativa à aquisição de acervos. Pesquisadores inseridos nos campos da História e do Direito identificam os acervos judiciais relevantes para a pesquisa, negociam a sua transferência temporária para o Labdoc, onde são conduzidos os processos de desinfestação, higienização e restauração, quando necessário. Em seguida, é feita a identificação, organização e indexação em base de dados informacional. O retorno da documentação aos fóruns é feita após serem firmados convênios, nos quais fica registrado o compromisso da instituição com a construção ou adequação de espaço adequado para guarda e consulta do acervo. Ver em: VELLASCO, Ivan Andrade. Uma experiência pioneira com arquivos judiciais. Revista do Arquivo Público Mineiro, Belo Horizonte, v.46, n.1, p.24-35, janeiro/junho, 2010.

18 BERTHOLDO, Flávio Augusto Rocha. Uma plataforma de pesquisa amplamente disponível. Revista do Arquivo Público Mineiro, Belo Horizonte, v.46, n.1, p.138-147, janeiro/junho 2010.

19 SANTANA, Emerson Nogueira. Acesso livre à informação pública. Revista do Arquivo Público Mineiro, v.46, n.1, p.130, janeiro/junho, 2010

20 No plano das bibliotecas, cabe ressaltar que a Biblioteca Nacional começou a investir numa política de digitalização de seu acervo partir de 2003, portanto num período simultâneo ao projeto da CLD. Ver: FONSECA, Paulo Miguel e MARTINS, Vinícius Pontes. Disseminação da cultura em meio digital. Revista do Arquivo Público Mineiro, Belo Horizonte, v.46, n.1, p.68-79, janeiro/junho, 2010. 
mesma sensação, pois os projetos estavam se desenvolvendo quase simultaneamente. ${ }^{21}$ Portanto, os problemas encontrados pelos usuários da CLD, notadamente os de acesso à base de dados, não diferem de outros problemas narrados na literatura recente.

A introdução expressiva dos recursos eletrônicos nas últimas décadas permitiu a disponibilidade de obras e de fontes de informação em meio digital estabelecendo várias possibilidades de armazenamento e acesso. Nesse contexto, as bibliotecas digitais são ambientes complexos que interagem e exigem parâmetros, padrões internacionais que garantam sua interoperabilidade de conteúdos, de busca e recuperação e oferta de serviços. ${ }^{22}$

Para concretização de uma Coleção Digital Linhares efetiva, além do aspecto de repositório de preservação e disseminação de informações, o grande desafio é a interoperabilidade que permitira ao "usuário acessar consistentemente e coerentemente classes de objetos similares e serviços digitais distribuídos a partir de repositórios heterogêneos". ${ }^{23}$

Essa interoperabilidade depende fortemente de processos baseados em padrões abertos e bem documentados e de interação entre instituições e grupos de pesquisadores, em fóruns especiais para decidir e estabelecer um conjunto de padrões, protocolos formatos e melhores práticas - ações estruturantes e de regulamentação que proporcionem suportes à criação de novos repositórios e estabeleçam mecanismos para integrar os já existentes como a CLD.

Encerramos este artigo enfatizando o papel de grande importância da imprensa, ao registrar e acompanhar o desenrolar dos fatos cotidianos, sejam eles políticos, econômicos, sociais ou culturais. Nessa perspectiva, enquadra-se a Coleção Linhares. A preservação e conservação a partir da microfilmagem e digitalização de tão significativos documentos é a certeza de que garantiremos para a comunidade usuária (estudantes, pesquisadores, pessoas em geral) um acervo referencial que registra uma parte significativa da história de Belo Horizonte contada através de seu cotidiano. A preservação da monografia de Linhares não se esgota, entretanto, com a criação da CLD. Se a tecnologia é vista por muitos como efêmera, é nossa função alertar os atuais e futuros pesquisadores para que fiquem atentos, em atitude de fiéis guardiães da coleção de Linhares em meio digital. Pois o sentimento mais genuíno de todos que a conhecem é o de sua permanência no presente e no futuro.

21 Aqui nos referimos de maneira pontual aos projetos contemplados pelo Edital EDT 1866/02 no âmbito do Programa "Uso da Tecnologia Digital no Resgate da Identidade Histórico-cultural de Minas Gerais", da Secretaria de Estado de Ciência e Tecnologia e Ensino Superior - SECTS/MG.

22 SAYÃO, Luiz Fernando. Padrões para Bibliotecas Digitais abertas e interoperáveis. Encontros Bibli: revista eletrônica de biblioteconomia e ciências da informação, Florianópolis, n. Especial, p.18-47, primeiro semestre de 2007.

23 SAYÃO, Luiz Fernando. Padrões para Bibliotecas Digitais abertas e interoperáveis, p.18-47. 